\title{
SOBRE A FILOSOFIA DA HISTÓRIA DE WALTER BENJAMIN
}

Pedro Leal Gomes

\section{RESUMO}

A partir de uma reflexão acerca da filosofia da história de Walter Benjamin, tendo como lastro os textos Experiência e Pobreza (1933), O narrador (1936) e Sobre o conceito de história (1940), se tematizará principalmente as ideias de experiência, narração, rememoração e redenção. Nesse sentido, será abordado o declínio da experiência na modernidade, a crise da narração, a crítica ao historicismo e a proposição de um materialismo histórico redentor, reivindicando uma compreensão não-linear dos textos benjaminianos e percebendo nas suas contradições - ou diferentes visões, sobre a mesma questão - uma virtude.

Palavras-chave: Filosofia da História, Walter Benjamin, Experiência, Narração, Redenção.

\section{ABOUT WALTER BENJAMIN'S PHILOSOPHY OF HISTORY}

\begin{abstract}
Starting from a speculation concerning Walter Benjamin's philosophy of history, taking for granted texts such as Experiência e Pobreza (1933), O narrador (1936) e Sobre o conceito de história (1940), the primarily focus will be on the ideas of experience, narration, remembrance and redemption. In this sense, it'll be approached the modernity's experience decay, the narrative's crisis, the critique to historicism and the redeemer historical materialism's proposition. Claiming a non-linear understanding of the benjaminian's texts and realizing in its contradictions - or different visions about the same issue - a virtue.
\end{abstract}

Key Words: Philosophy of History, Walter Benjamin, Experience, Narration, Redemption.

Pedro Leal Gomes. Graduando em História pela Universidade Federal de Santa Maria - UFSM. Bolsista de iniciação científica no projeto História, Presença e Sentido, coordenado pelo Prof.

Dr. Carlos Henrique Armani. Brasileiro, reside em Santa Maria - RS. Email: 


\begin{abstract}
"A verdadeira imagem do passado passa voando. O passado só se deixa capturar como imagem que relampeja irreversivelmente no momento de sua conhecibilidade."
\end{abstract}

Walter Benjamin

\title{
Introdução
}

Walter Benjamin (1892-1940) não foi o primeiro e nem será o último filósofo a escrever sobre a História. Sendo um autor lido por diversas áreas do conhecimento, ou seja, seu repertório de escrita fazendo-se bastante amplo, ele carrega inquestionáveis contribuições para a teoria e filosofia da história. A ocorrência de Benjamin escrever sobre múltiplos assuntos pode ser relacionada com o fato de ser um pensador que tem diversas influências, tidas por alguns, inclusive, como contraditórias. Michel Lowy afirma que "Ele é um crítico revolucionário da filosofia do progresso, um adversário marxista do "progressismo", um nostálgico do passado que sonha com o futuro, um romântico partidário do materialismo. Ele é, em todas as acepções da palavra, "inclassificável". (...) Sua obra se apresenta, realmente, como uma espécie de bloco errático à margem das grandes tendências da filosofia contemporânea." (LOWY, 2005, p. 8). Tendo como foco principalmente os textos Experiência e Pobreza (1933), O narrador (1936) e Sobre o conceito da história (1940) propõese uma discussão acerca da filosofia da história de Walter Benjamin, as ideias de experiência, narração, rememoração e redenção.

Antes de entender a filosofia da história de Benjamin como uma contrahistória, ou um sistema explicativo fechado e coerente internamente, é necessário vê-la como crítica, ou como"produção de rupturas eficazes" e "um abalo, um choque que imobiliza o desenvolvimento falsamente natural da narrativa" (GAGNEBIN, 2013, 103-104). Dois abalos são nítidos em sua filosofia da história: o primeiro deles é o ataque a ideia de causalidade histórica. 0 esforço de Benjamin é mostrar que essa visão dos fatos, aliada a uma visão de 
progresso, transforma a História em um somatório de acontecimentos, preenchidos por um tempo homogênio e vazio. A segunda ruptura tem como alvo uma leitura épica da História, a saber, a propensão a enxergar uma harmonia universal, ou um significado infinito que abarca toda a História em seu sentido último, retirando assim o caráter de finitude, ou mesmo de limite da própria linguagem. Assim, Benjamin "impõe uma advertência imperiosa a esta pretensão de absoluto e de infinito de um discurso que funda sua competência no seu próprio desenvolvimento; pela parada, pela queda súbita da linguagem, ela marca seu fim, sua morte e o que, nessa última exaustão, seria sua fonte indizível." (GAGNEBIN, 2013, 106)

Percebendo alguns sintomas da modernidade - a crise da experiência, e a decadência das narrativas tradicionais -, Benjamin sai em busca de uma compreensão relativa às próprias noções de narração e experiência, em vias de propor rupturas criativas a esses problemas diagnosticados por ele, ou seja,

como descrever essa atividade narradora que salvaria o passado, mas
saberia resistir à tentação de preencher suas faltas e de sufocar seus
silêncios? Qual seria essa narração salvadora que preservaria, não
obstante, a irredutibilidade do passado, que saberia deixá-lo
inacabado, assim como, igualmente, saberia respeitar a
imprevisibilidade do presente? (GAGNEBIN, 2013,63)

$E$, certamente, como marxista que Benjamin foi, essas adversidades tem relação com o avanço do capitalismo moderno, de uma contínua exploração dos subalternos, tanto social, cultural, economica e politicamente; abuso que se encontra enraizado no próprio conhecimento produzido.

\section{Experiência e Narração}

Imaginando que o narrador vem de longe, dizem que "Quem viaja tem muito que contar. Apesar de captar essa figura, Benjamin percebe que também é prazeroso quando se escuta uma pessoa que viveu toda sua vida sem sair de seu país, e conhece suas histórias e tradições. Seja um camponês sedentário ou um marinheiro comerciante - não limitando-se a esses exemplos e formas de 
narrar -, esses tipos fazem parte do reino da narração. Para Benjamin, é imprescindível vislumbrar na narração a experiência, "o narrador retira o que ele conta da experiência: de sua própria experiência ou da relatada por outros. E incorpora, por sua vez, as coisas narradas à experiência dos seus ouvintes." (BENJAMIN, 217, 2012). Se levarmos em conta a experiência como fundamento da narrativa, podemos perceber o caráter infindável da mesma, ou seja, a narrativa não se esgota em si, como por exemplo, a informação. A informação vive no momento de sua breve relevância e novidade, na medida em que explica algo; a narrativa, segundo Benjamin, não necessita de explicação, pois está fundada na experiência e pode ser captada e interpretada de diversas formas, desdobrando-se criativa e continuadamente.

Inaugurando seu texto Experiência e Pobreza (1933), Benjamin discorre sobre uma antiga parábola, mencionando a história de um velho, que prestes a morrer, conta a seus filhos sobre um tesouro até então secreto em seus vinhedos. Após cavarem, os filhos não encontram nenhum tesouro. Somente com a chegada do inverno e por ser sido a produção das vinhas maior da região, eles compreenderam. A felicidade não estava no ouro, mas no trabalho duro. Esse é um exemplo de experiência compartilhada, assim como diversas dessas experiências foram partilhadas, antes de dormir ou ao redor da lareira, por familiares a nós mesmos. Até então estava lúcido o significado dessas experiências, baseadas numa temporalidade, ou seja, num conhecimento advindo do tempo vivido, passado de geração em geração, ou de pessoa para pessoa, através do ato de narrar. Para Benjamin, essa forma da narrar está em crise. Em crise, primeiramente, pois há o avanço deturpante da técnica e uma contínua despersonalização humana frente ao tempo de trabalho e ao capitalismo; em segundo lugar, relacionada a própria crise da experiência, ou seja, se as formas tradicionais de narração estão rarefeitas ou mesmo ausentes, a crise da experiência é basilar nesse processo. E não só crise da experiência individual, como quando Benjamin afirma, usando o clássico exemplo dos soldados que voltaram dos campos de batalha "mais pobres em experiência comunicáveis, e não mais ricos." (BENJAMIN, 2012, 124), mas também das 
experiências da humanidade em geral. Colocando um novo e positivo conceito de Barbárie, Benjamin enxerga uma saída na medida em que

o que resulta para o bárbaro dessa pobreza de experiência? Ela o impele a partir para a frente, a começar de novo, a contentar-se com pouco, a construir com pouco, sem olhar nem para a direita nem para a esquerda. Entre os grandes criadores sempre existiram aqueles implacáveis que operaram a partir de uma tábula rasa. Pois queriam uma prancheta: foram construtores (...) Aqui e ali, as melhores cabeças já começaram há tempos a expressar essas coisas. Sua característica é uma desilusão radical com a época e ao mesmo tempo uma fidelidade sem reservas a ela. (BENJAMIN, 2012, 125)

Nesse texto, diferentemente de em $O$ narrador (1936), a resposta para essa crise divide-se em duas, inicialmente se dá a partir da difusão de valores individuais e privados, substituindo os valores e as crenças coletivas, "a história vai, pouco a pouco, preencher o papel deixado vago pela história comum" (GAGNEBIN, 2013, 59). É nesse contexto que Benjamin propõe um novo conceito de experiência. Em vez de Erfahrung (experiência), vem a Erlebnis (vivência), pois essa vivência coloca-se em relação a essas novas formas sociais; uma nova maneira de estar no mundo, que é individual e solitária. Em seguida, segue-se a essa interiorização individual, o que Gagnebin chama de interiorização espacial, a saber, uma valorização do interior pela arquitetura,

a casa particular torna-se uma espécie de refúgio contra um mundo exterior hostil e anônimo. O indivíduo burguês, que sofre de uma espécie de despersonalização generalizada, tenta remediar este mal por uma apropriação pessoal e personalizada redobrada de tudo o que Ihe pertence no privado: suas experiências inefáveis (Erlebnisse), seus sentimentos, sua mulher, seus filhos, sua casa e seus objetos pessoais (...) Despossuído do sentido da sua vida, o indivíduo tenta, desesperadamente, deixar a marca de sua possessão nos objetos pessoais: iniciais bordadas num lenço, estojos, bolsinhos, caixinhas, tantas tentativas de repetir no mundo dos objetos o ideal de moradia. Benjamin observa com humor que o veludo não é por acaso um dos materiais preferidos dessa época: os dedos do proprietário deixam nele, facilmente, seu rastro. (GAGNEBIN, 2013, 59 e 60)

Seja através de uma interiorização individual ou espacial, o que é visível nessas respostas é uma supressão da experiência pela vivência, a individualização do próprio experienciar termina por esfacelar a narrativa tradicional.

Pedro Leal Gomes. Graduando em História pela Universidade Federal de Santa Maria - UFSM. Bolsista de iniciação científica no projeto História, Presença e Sentido, coordenado pelo Prof.

Dr. Carlos Henrique Armani. Brasileiro, reside em Santa Maria - RS. Email: 
É em O narrador (1936) que Benjamin rejeita seu próprio conceito positivo de Barbárie, e propõe uma alternativa a partir do fim da experiência e das narrativas tradicionais. Percebendo que a substituição da vivência em detrimento da experiência e a divisão da narrativa coletiva em várias outras - objetivas, heroificadas, informativas - não é uma resposta satisfatória, e não se propondo a paralisar-se em vista ao passado longínquo e belo, de maneira nostálgica, Benjamin mantém o esforço de reflexão. Reconhecendo que o filósofo não é meramente um saudosista, seu objetivo não é somente explicitar a decadência de uma época, ou mostrar a falência de uma forma de comunicação, mas sim

\begin{abstract}
de detectar na antiga personagem, hoje desaparecida, do narrador, uma tarefa sempre atual: a da apokatastasis, essa reunião de todas almas no Paraíso, segundo a doutrina (condenada por heresia) de Orígenes, uma doutrina que teria tanto influenciado Leskov. Recolhimento que o narrador, essa figura secularizada do Justo, efetuaria por suas narrativas, mas, singularmente, que definirá também o esforço do historiador "materialista", tal como o chama Benjamin nas "Teses". (GAGNEBIN, 2013, 62)
\end{abstract}

Assim, a nova resposta benjaminiana brada por uma narração que esteja ligada à própria constituição do sujeito, ou seja, à rememoração, à retomada da palavra salvadora pela palavra de um passado que, sem isso, desapareceria no silêncio e no esquecimento (GAGNEBIN, 2013, p. 3). Afinal, é por uma narração, ou por uma escrita da História redentora que Benjamin luta. Por uma história à contrapelo, que inverta a lógica epistemológica dos vencedores, e não apenas conte a história dos vencidos, mas salve suas memórias.

\title{
2 Rememoração e Redenção
}

Não à toa Agamben afirma que Benjamin - assim como Heidegger - é uma das pessoas que inovam ao pensar sobre o tempo na contemporaneidade ${ }^{1}$; segundo ele, Benjamin percebe na concepção de tempo - principalmente moderna, mas não só - uma linearidade infinita, que iria progredindo

\footnotetext{
${ }^{1}$ Agamben, 2005, 124-125.

Pedro Leal Gomes. Graduando em História pela Universidade Federal de Santa Maria - UFSM. Bolsista de iniciação científica no projeto História, Presença e Sentido, coordenado pelo Prof. Dr. Carlos Henrique Armani. Brasileiro, reside em Santa Maria - RS. Email:
} 
indefinidamente até uma novidade. Esse regime temporal, materializado na crítica de Benjamin aos historicistas e à social-democracia alemã, causa não apenas uma visão errônea da História, como - no caso da social-democracia a própria abertura ao avanço nazista na Alemanhã da primeira metade do século XX. Ao entender que há um progresso a priori, o futuro está fechado num otimismo ingênuo, e não há necessidade da luta no presente. Benjamin contrapõe essa ideia de temporalidade vazia e homogênia, com um instante que rompe o continuum da História, com o tempo-de-agora (Jetztzeit).

Em Benjamin opera aquela mesma intuição messiânica do hebraísmo que levara Kafka a escrever que "o Dia do Juízo é a condição histórica normal" e a substituir a ideia da história desenrolando-se ao longo do tempo linear infinito pela imagem paradoxal de um "estado da história", cujo evento fundamental está sempre em curso e cuja meta não se encontra distante no futuro, mas já sempre presente. Retomando esses temas, Benjamin busca uma concepção da história correspondente à constatação de que "o estado de emergência é a regra". Benjamin substitui o presente nulificado da tradição metafísica por "um presente que não é passagem, mas que se mantem imóvel no limiar do tempo" (AGAMBEN, 2005, 124-125)

Desta forma, Benjamin clama por uma escrita da História que perceba o momento exato em que a História se apresenta, momento que se dá no presente, e para ele, essa é a tarefa do historiador e da historiadora materialista. É através da rememoração - e de uma posterior redenção - que isso se dará. Rememoração, primeiro, dos vencidos; para Benjamin, a História tem sido a História dos vencedores, daí a necessidade de um olhar à contrapelo, que inverta a lógica da historiografia e perceba os subalternos, os esquecidos da História. E segundo, rememoração das ausências e das possibilidades, pois

A mera possibilidade dá vida a um passado que parecia acabado, porque sua "ausência" questiona a legitimidade do fático ao mesmo tempo que permite à injustiça passada fazer-se presente como demanda de justiça. Porque o passado poderia ter sido de outra maneira, o que agora existe não deve ser visto como uma fatalidade que não se pode mudar. E se o presente tem uma possibilidade latente que vem de um passado que não pôde ser, sendo que podemos imaginar, então, um futuro que não seja projeção do seu presente dado, mas do presente possível." (MATE, 2011, 24)

Pedro Leal Gomes. Graduando em História pela Universidade Federal de Santa Maria - UFSM. Bolsista de iniciação científica no projeto História, Presença e Sentido, coordenado pelo Prof.

Dr. Carlos Henrique Armani. Brasileiro, reside em Santa Maria - RS. Email: 
É vislumbrando através das ausências que podemos imaginar possíveis futuros de possíveis presentes. E para Benjamin, não basta apenas o futuro ser melhor, não basta que uma utopia qualquer se concretize, é necessário que as gerações que foram pisoteadas para que isso acontecesse, sejam redimidas.

É primordial perceber em Benjamin que a preocupação com os excluídos da História, das gerações esquecidas, das ausências, não é meramente epistemológica e referente à coerência do discurso histórico, mas é uma necessidade de rememoração ética e política. E não há felicidade num futuro que não leve em consideração esse passado reprimido, uma vez que

\begin{abstract}
há uma continuidade entre os que lutaram no passado pela democracia e a democracia atual. Muitos tiveram que morrer e ver seus ideias serem derrotados para que um dia nós pudéssemos viver na democracia. Pois bem, o que Benjamin quer nos dizer é que, sem a memória e o reconhecimento dessas mortes, nunca entenderemos 0 que agora desfrutamos. A responsabilidade não nasce de uma reflexão metafísica, como em Lévinas, mas da consciência histórica." (MATE, 2011, 102)
\end{abstract}

Além de perceber a injustiça passada e presente, em vias de uma transformação do agora, é necessário que a força messiânica da redenção possa fazer justiça a essa injustiça passada.

\title{
CONCLUSÃO
}

É na paradoxal relação entre o fim das formas tradicionais de experienciar o mundo e de formular narrativas, e na necessidade ética e política da rememoração redentora, ou seja, de uma outra maneira de escrever a História, que a filosofia da história benjaminiana se compõe. Crítica das concepções progressistas que esvaziam o tempo, essa filosofia não pretende jamais ser sistemática e abarcar o todo; ela é, inclusive, crítica de si mesma. Por certo, não se abarcará toda sua complexidade e riqueza, deixando-a em aberto, assim como ela mesma se coloca, dado que

não conseguiremos definir com uma completa exatidão qual seria esta
narração salvadora e transformadora que deveria ser o paradigma de
uma nova historiografia e a que Benjamin faz apelo nas "Teses". Pelo
menos, e isso talvez importe mais, não teremos atenuado a

Pedro Leal Gomes. Graduando em História pela Universidade Federal de Santa Maria - UFSM. Bolsista de iniciação científica no projeto História, Presença e Sentido, coordenado pelo Prof. Dr. Carlos Henrique Armani. Brasileiro, reside em Santa Maria - RS. Email: 
radicalidade desta questão, nem sufocado a esperança e a exigência que ela implica. (GAGNEBIN, 2013, 6)

Deste modo, Benjamin se mostra tanto como um pessimista ao perceber o fim da experiência e narração moderna, e o momento da barbárie na meia noite na história ${ }^{2}$, como um otimista ao perceber na tarefa da historiadora e do historiador materialista a chance de salvação das gerações massacradas no passado - e no presente -.

É no narrador, no historiador e na historiadora materialista que Benjamin coloca essa responsabilidade,

o cronista [narrador] que narra os acontecimentos, sem dinstinguir entre os grandes e os pequenos, leva em conta a verdade de que nada do que um dia aconteceu pode ser considerado perdido para a história. Sem dúvida, somente a humanidade redimida obterá o seu passado completo. Isso quer dizer: somente para a humanidade redimida o seu passado tornou-se citável, em cada um dos seus momentos. Cada um dos seus momentos vividos transforma-se numa citation à l'ordre $d u$ jour - e esse dia é justamente o do juízo final. (BENJAMIN, 2012, 242)

Quando a História rememorar as catástrofes, quando lembrar suas ruínas, suas ausências e esquecimentos, é quando o anjo da história finalmente se deterá para acordar os mortos e juntar seus fragmentos. Esse é o dia do juízo final benjaminiano.

\section{REFERÊNCIAS}

AGAMBEN, Giorgio. Infância e história: destruição da experiência e origem da história. Belo Horizonte: UFMG. 2005

BENJAMIN, Walter. "O narrador". Considerações sobre a obra de Nikolai Leskov. In: Magia e técnica, arte e política: ensaios sobre literatura e história da cultura (Obras escolhidas v. 1). São Paulo: Editora Brasiliense, 2012. p. 213-240.

\footnotetext{
2 Expressão que se refere ao contexto vivido por Benjamin, principalmente acerca do avanço do nazi-fascismo e o esfacelamento das democracias.

Pedro Leal Gomes. Graduando em História pela Universidade Federal de Santa Maria - UFSM. Bolsista de iniciação científica no projeto História, Presença e Sentido, coordenado pelo Prof. Dr. Carlos Henrique Armani. Brasileiro, reside em Santa Maria - RS. Email:
} 
. "Experiência e pobreza". In: Magia e técnica, arte e política: ensaios sobre literatura e história da cultura (Obras escolhidas v. 1). São Paulo: Editora Brasiliense, 2012, p. 123-128.

. "Sobre o conceito da História". In: Magia e técnica, arte e política: ensaios sobre literatura e história da cultura (Obras escolhidas v. 1). São Paulo: Editora Brasiliense, 2012, p. 241-252.

GAGNEBIN, Jeanne Marie. História e narração em Walter Benjamin. São Paulo: Editora Perspectiva, 1999.

LÖWY, Michael. Walter Benjamin: aviso de incêndio: uma leitura das teses "Sobre o conceito da história". São Paulo: Boitempo, 2005.

MATE, Reyes. Meia-noite na história. Comentários às teses de Walter Benjamin 'Sobre o conceito de história'. São Leopoldo/RS: Editora UNISINOS, 2011. 